\title{
A role of ${ }^{18} \mathrm{~F}$-fluorodeoxyglucose positron emission/computed tomography in a strategy for abdominal wall metastasis of colorectal mucinous adenocarcinoma developed after laparoscopic surgery
}

\author{
Kimihiko Funahashi", Mitsunori Ushigome, Hironori Kaneko
}

\begin{abstract}
Metastasis to the abdominal wall including port sites after laparoscopic surgery for colorectal cancer is rare. Resection of metastatic lesions may lead to greater survival benefit if the abdominal wall metastasis is the only manifestation of recurrent disease. A 57-year-old man, who underwent laparoscopic surgery for advanced mucinous adenocarcinoma of the cecum 6 years prior, developed a nodule in the surgical wound at the lower right abdomen. Although tumor markers were within normal limits, the metastasis to the abdominal wall and abdominal cavity from the previous cecal cancer was suspected. An abdominal computed tomography scan did not provide detective evidence of metastasis. ${ }^{18} \mathrm{~F}$-fluorodeoxyglucose positron emission/computed tomography $\left({ }^{18} \mathrm{~F}\right.$-FDG PET/CT) was therefore performed, which demonstrated increased ${ }^{18} \mathrm{~F}$-fluorodeoxyglucose uptake (maximum standardized uptake value: 3.1 ) in the small abdominal wall nodule alone. Histopathological examination of the resected nodule confirmed the diagnosis of metastatic mucinous adenocarcinoma. Prognosis of intestinal mucinous adenocarcinoma is reported to be poorer than that of non-mucinous adenocarcinoma. In conclusion, this case suggests an important role of ${ }^{18} \mathrm{~F}-\mathrm{FDG}$ PET/CT in early diagnosis and decision-making regarding therapy for recurrent disease in cases where a firm diagnosis of recurrent colorectal cancer is difficult to make.
\end{abstract}

\section{Background}

Metastasis to the abdominal wall including port sites after laparoscopic surgery for colorectal carcinoma (CRC) is rare. Recently the rate was reported as $1.3 \%$ in a randomized clinical trial by the Colon Cancer Laparoscopic or Open Resection Study Group [1] and 2.4\% in the CLASSIC trial [2]. Although the prognosis is not clearly defined in the literature, resection of metastatic lesions may lead to greater survival benefit if the abdominal wall metastasis is the only manifestation of recurrent disease. However, it can be difficult to diagnose a lesion in the abdominal wall as recurrence of disease on the basis of clinical characteristics alone. Approximately between $5 \%$ to $15 \%$ of CRCs are mucinous adenocarcinomas [3-7]. Patients with colorectal

\footnotetext{
* Correspondence: kingkong@med.toho-u.ac.jp

Department of Gastroenterological Surgery, Toho University Medical Center, Omori Hospital, 6-11-1 Omori nishi, Otaku, Tokyo, 143-8541, Japan
}

mucinous adenocarcinoma are reported to have a poorer prognosis compared to patients with non-mucinous adenocarcinoma because the greater frequency of lymph node involvement and peritoneal dissemination seen with mucinous adenocarcinoma [7-10]. Therefore, Patients with mucinous adenocarcinoma should be followed carefully after surgery, and receive rapid diagnosis and treatment if recurrence is suspected. We report a case in which ${ }^{18} \mathrm{~F}$ fluorodeoxyglucose positron emission/computed tomography $\left({ }^{18} \mathrm{~F}\right.$-FDG PET/CT) was very useful for early diagnosis and planning a theraupetic strategy for a case of mucinous adenocarcinoma metastasis at a laparoscopic port site.

\section{Case presentation}

A 57-year-old man received curative laparoscopic ileocecal resection and lymph node dissection for carcinoma of the cecum in May 2004. Morphologically, the tumor 
was type I ( $45 \mathrm{~mm}$ by $30 \mathrm{~mm}$ ). The histological examination revealed a mucinous adenocarcinoma which invaded the cecal subserosa. Tumor cells were not identified histologically in the 20 regional lymph nodes, surgical margins, lymph vessels, or veins of the surgical specimens (pT3 N0 M0). The patient was subsequently followed at our hospital and treated with oral 5-fluorouracil. In February 2008, the patient discovered a nodule in the incision site in the lower right abdomen. A 2-cm, firm, ill-defined, tender mass was palpable in the incision site, and was suspected to be a recurrence of the cecal mucinous adenocarcinoma. However, the levels of carcinoembryonic antigen (CEA) and carbohydrate antigen 19-9 (CA19-9) were within normal limits (CEA: $4.7 \mathrm{ng} / \mathrm{dl}, \mathrm{CA19-9:} 16.2 \mathrm{U} / \mathrm{ml}$ ). In November 2008, an abdominal computed tomography (CT) scan revealed a small nodule in the abdominal wall, which was difficult to interpret as metastasis of the cecal cancer (Figure 1). 18F-fluorodeoxyglucose $\left({ }^{18} \mathrm{~F}\right.$-FDG) positron emission/computed tomography (PET/CT) was performed in January 2009. The CT scan was performed first, from head to pelvic floor using $3.3-\mathrm{mm}$ section thickness. Immediately after the CT scan, a PET scan was performed using the identical transverse field of view and section thickness as that of the $\mathrm{CT}$ scan. For the PET scan, the patient, whose blood glucose level was $103 \mathrm{mg} / \mathrm{dl}$, received $181.8 \mathrm{MBq}$ of ${ }^{18} \mathrm{~F}$-FDG intraverously. Data acquisition was performed within $20 \mathrm{~min}$ after injection using an integrated PET/CT system (Eminence SOPHIA; Shimadzu Corporation, Kyoto, Japan). PET image data sets were reconstructed by ${ }^{137}$ caesium for attenuation correction, and coregistered images were displayed. The PET/CT scan demonstrated increased ${ }^{18} \mathrm{~F}$ FDG uptake (maximum standardized uptake value: 3.1 )

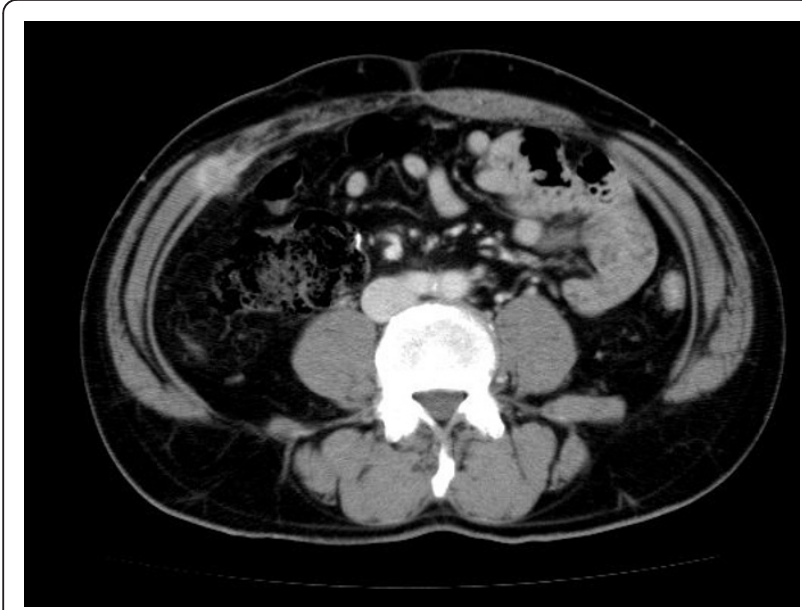

Figure 1 Abdominal computed tomography scan. Abdominal computed tomography scan on November 2008 revealed a small nodule in the abdominal wall, which was difficult to interpret as metastasis of cecal cancer by only computed tomography image. in the small abdominal nodule, but no further metastases in distant organs, peritoneum, or lymph nodes. The small nodule was diagnosed as a solitary metastasis of the cecal cancer at the previous port site (Figure 2). The nodule was resected in February 2009. The tumor was located in the abdominal wall, slightly exposed to the abdominal cavity. There was no gross evidence of metastasis in the abdominal cavity and cytological examination identified no tumor cells in the ascitic fluid. The tumor was identified as a metastatic lesion on the basis of histological findings (Figures 3, 4 and 5). No recurrence developed during 24months postsurgical follow up.

\section{Discussion}

Port site metastasis after laparoscopic surgery for CRC is rare, reported as $0.71-1 \%$ in the literature [11-16]. Recently the rate was reported as $1.3 \%$ in a randomized clinical trial by the Colon Cancer Laparoscopic or Open Resection Study Group [1] and 2.4\% in the CLASSIC trial [2]. Several factors that may contribute to abdominal wall metastasis have been proposed [17], but it was impossible to identify a cause in this case. The operating record indicated that a wound drape had been used to prevent the implantation of tumor cells during surgery; clinico-pathologically, the depth of invasion of the primary tumor was confined to the intestinal wall and no vascular invasion was identified, and there were no postoperative complications.

Early resection of the metastatic lesion may lead to greater survival benefit, but early confirmation of metastatic disease on the basis of clinical characteristics alone is challenging. ${ }^{18} \mathrm{~F}$-FDG PET/CT imaging, which both structural and functional information provide, is

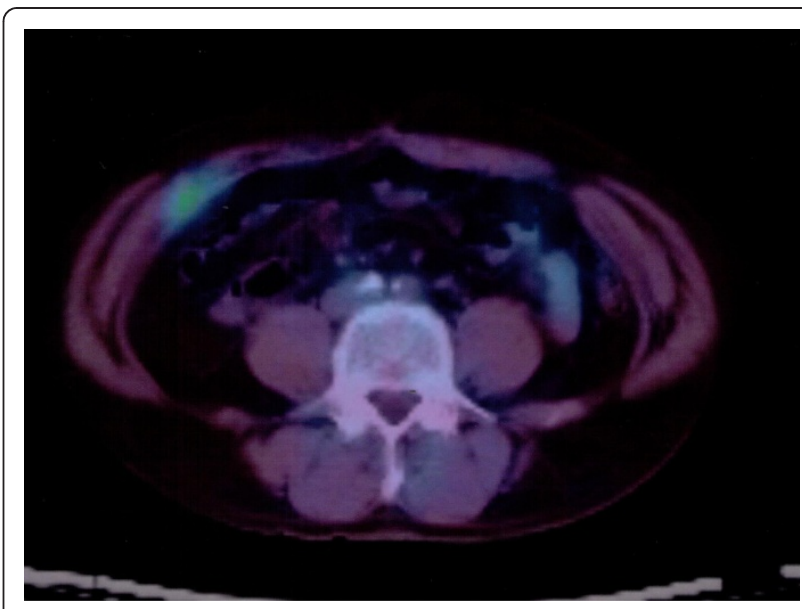

Figure $2{ }^{18} \mathrm{~F}$-fluorodeoxyglucose positron emission/computed tomography. ${ }^{18}$ F-fluorodeoxyglucose positron emission/computed tomography demonstrated increased ${ }^{18} \mathrm{~F}$-fluorodeoxyglucose uptake (maximum standardized uptake value: 3.1 ) in the small nodule in the abdominal wall. 


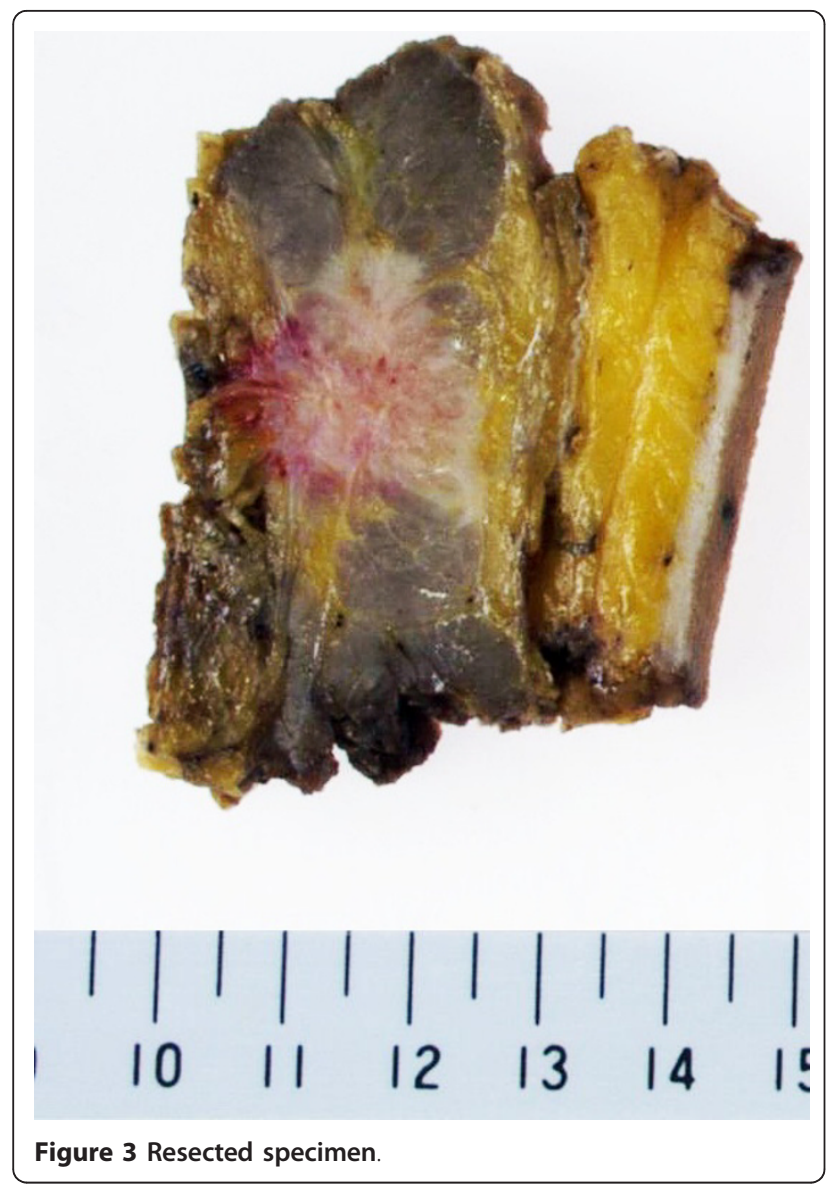

used to identify and stage various types of tumors because of its superiority to traditional imaging for diagnosing recurrent disease. In a retrospective comparison of PET versus PET/CT for the detection of CRC recurrence, the sensitivity, specificity and overall accuracy of PET were $80 \%, 69 \%$ and $75 \%$ respectively, compared with $89 \%, 92 \%$ and $90 \%$, respectively, for PET/CT [18]. Goshen et al [19] reported ${ }^{18} \mathrm{~F}$-FDG PET/CT was a sensitive tool for the diagnosis of 16 abdominal wall lesions in 12 CRC patients, who had moderately or well-differentiated adenocarcinoma. Kozugi et al reported that ${ }^{18} \mathrm{~F}$ FDG PET was an important tool for the detection of port site recurrence of colon cancer in a patient who had elevated serum CEA levels but no metastases detected using routine radiographic examinations [20]. In addition, Sarikaya et al retrospectively analyzed the usefulness of PET for patients with CRC and suspected tumor recurrence, but normal CEA levels, and found that the overall accuracy of PET was $76.9 \%$, and the positive predictive value was $84.6 \%$. They concluded that PET yielded high positive predictive value for recurrence CRC despite normal CEA levels, and should be considered early in the evaluation of patients with suspected tumor recurrence [21]. ${ }^{18} \mathrm{~F}$-FDG PET/CT is useful tool

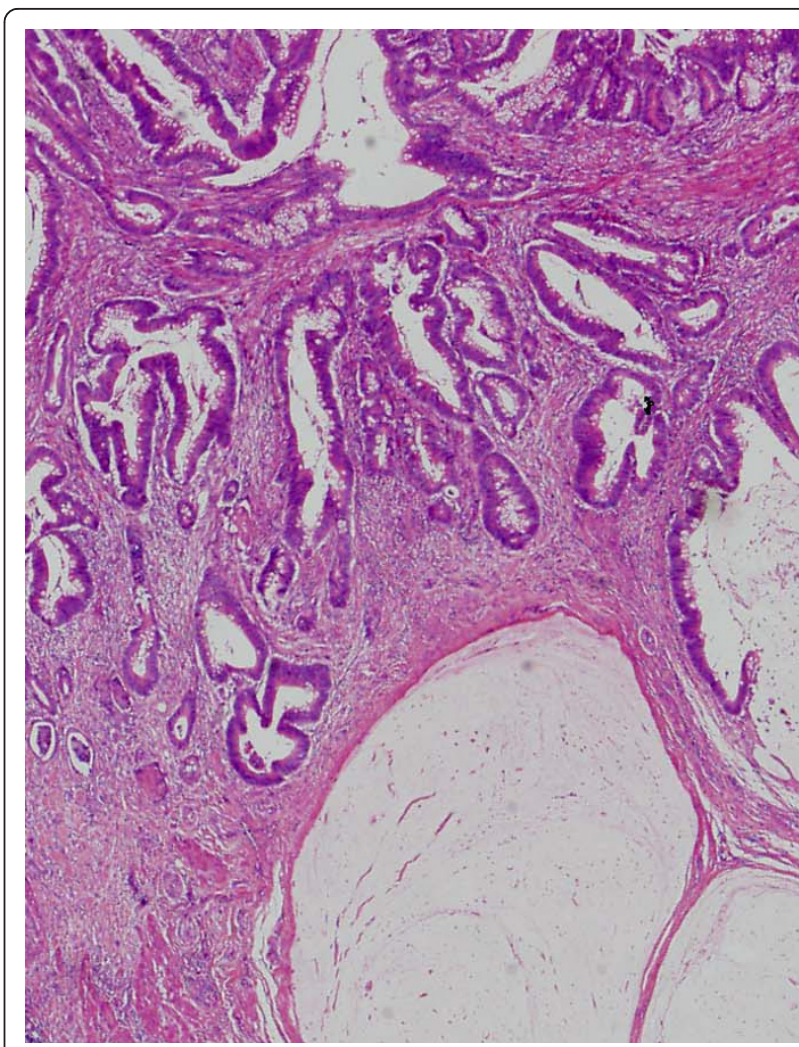

Figure 4 Pathological findings. Primary tumor. The histological examination revealed mucinous adenocarcinoma invading into the subserosa. Tumor cells in the regional lymph nodes, surgical margins, lymph vessels and veins were not identified histologically in the specimen (pT3 NO MO).

to help interpret potential malignancies when routine radiographic examinations are inconclusive. In addition, we consider that ${ }^{18} \mathrm{~F}$-FDG PET/CT should be a prerequisite examination in patients with suspected recurrence of CRC who have normal CEA levels.

${ }^{18}$ F-FDG PET/CT imaging, however, does have some disadvantages. False-negative findings can occur for several reasons, including inflammation, small lesions size and diabetes. Mucinous adenocarcinoma as a histological type, regardless of the organs, may result in more false negatives as well. Sarikaya et al [21] reported that 3 of 5 patients (60\%) with false-negative PET findings had mucinous adenocarcinoma diagnosed histologically. Rodriguez-Fernandez et al [22] and Sun L et al [23] reported false-negative results in patients with mucinous adenocarcinoma of the gallbladder and gastric cancer, respectively. For detection of gallbladder recurrence ${ }^{18} \mathrm{~F}$-FDG PET scan showed a sensitivity of $80 \%$, a specificity of $82 \%$, and positive and negative predictive values of $67 \%$ and $90 \%$, respectively. The single false-negative result was a patient with mucinous adenocarcinoma. For detection of gastric cancer recurrence, the accuracy of ${ }^{18}$ F-FDG PET/CT scan was $82.6 \%$, and positive and negative predictive values were $85.7 \%$ and $77.7 \%$, 


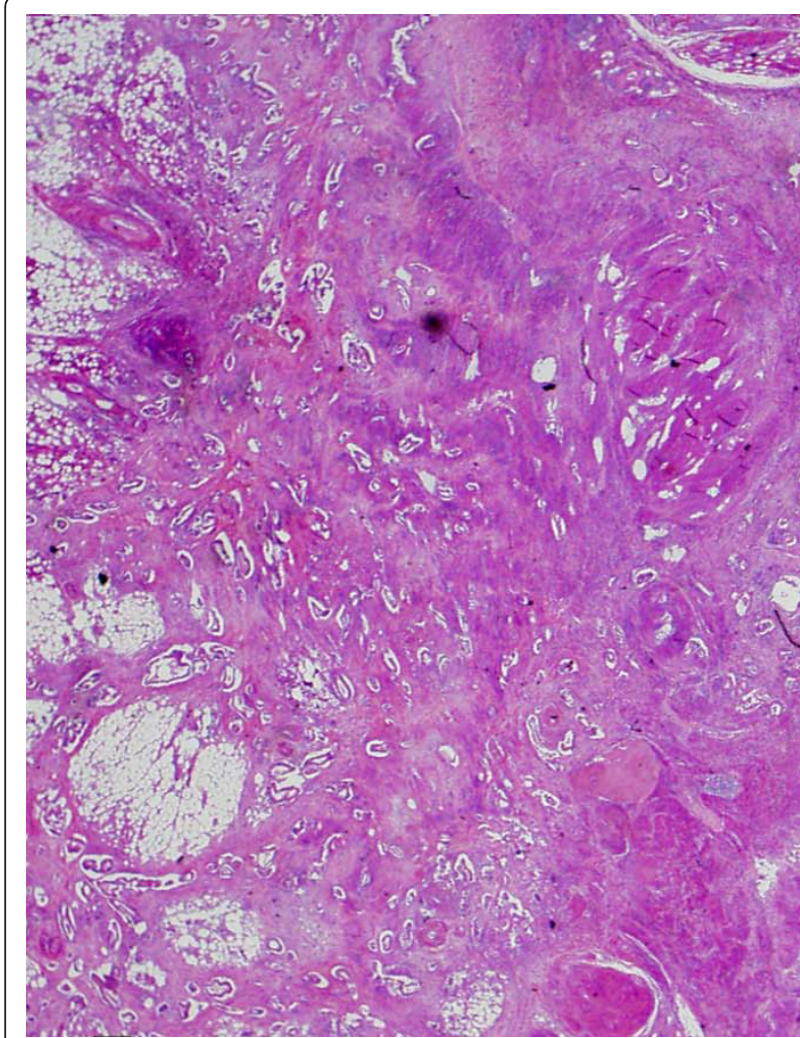

Figure 5 Pathological findings. Metastatic tumor. The tumor was located in the abdominal wall, slightly exposed to the abdominal cavity. Clinico-pathological findings showed the tumor was identified as a metastasis from cecal carcinoma.

respectively. The two false-negative in patients with mucinous adenocarcinoma as shown in these reports, and in our case study it can be difficult to detect lesions of mucinous adenocarcinoma by PET scan and ${ }^{18} \mathrm{~F}$-FDGPET/CT scan can be very useful in early diagnosis and therapeutic management.

Mucinous adenocarcinomas have a biological behavior that involves more lymph nodes at diagnosis and the greater frequency of peritoneal dissemination when compared to non-mucinous adenocarcinomas [7-10]. Recently, treatment with FOLFOX (Folinic acid + Fluorouracil + Oxaliplatin) or FOLFIRI (Folinic acid + Fluorouracil + Irinotecan) has been considered useful to obtain better progression-free survival for unresectable colorectal recurrence. However, there is no doubt that early complete resection of the metastatic lesion could lead to even greater survival benefit. ${ }^{18} \mathrm{~F}$-FDG PET/CT scan can play an important role in selecting among patients with recurrence those who may obtain greater survival benefit.

\section{Conclusion}

In the case we presented ${ }^{18}$ F-FDG PET/CT scan was very useful in early diagnosis and therapeutic management for recurrence of mucinous adenocarcinoma after laparoscopic surgery for CRC. Mucinous adenocarcinomas may contribute to a higher rate of false-negative results, but does not decrease the usefulness of this diagnostic tool. ${ }^{18}$ F-FDG PET/CT imaging, which provide both functional and anatomical information and correctly stages recurrence disease should be considered early in the evaluation of patients with suspected recurrence of CRC.

\section{Consent}

Written informed consent was obtained from the patient for publication of this case report and any accompanying image. A copy of the written consent is available for review by the Editor-in Chief of this journal.

\section{Abbreviations}

CRC: colorectal carcinoma; ${ }^{18} \mathrm{~F}$-FDG PET/CT: ${ }^{18} \mathrm{~F}$-fluorodeoxyglucose positron emission/computed tomography; ${ }^{18}$ F-FDG: ${ }^{18}$ F-fluorodeoxyglucose; PET/CT: positron emission/computed tomography; CEA: carcinoembryonic antigen; CA19-9: carbohydrate antigen 19-9; CT: computed tomography; PET: positron emission tomography; FOLFOX: Folinic acid + Fluorouracil + Oxaliplatin; FOLFIRI: Folinic acid + Fluorouracil + Irinotecan;

\section{Authors' contributions}

MU was an assistant of the operation. HK is a chairman of the department of gastroenterological surgery, Toho University Medical Center, Omori Hospital. All authors read and approved the final manuscript.

\section{Competing interests}

The authors declare that they have no competing interests.

Received: 3 October 2010 Accepted: 28 February 2011

Published: 28 February 2011

\section{References}

1. The Colon Cancer Laparoscopic or Open resection Study Group, Buunen M, Veldkamp R, Hop WC, Kuhry E, Jeekel J, Haglind E, Påhlman L, Cuesta MA, Msika S, Morino M, Lacy A, Bonjer HJ: Survival after laparoscopic surgery versus open surgery for colon cancer: long-term outcome of a randmised cilinical trial. Lancet Oncol 2009, 10:44-52.

2. Jayne DG, Thorpe HC, Copeland J, Quirke P, Brown JM, Guillou PJ: Five-year follow -up of the medical research council CLASSIC trial of laparoscopically assisted versus open surgery for colorectal cancer. $\mathrm{Br} J$ Surg 2010, 97:1638-1645.

3. Symonds DA, Vickery AL: Mucinous carcinoma of the colon and rectum. Cancer 1976, 37:1891-1900.

4. Fante R, Benatti P, di Gregorio C, De Pietri S, Pedroni M, Tamassia MG, Percesepe A, Rossi G, Losi L, Roncucci L, Ponz de Leon M: Colorectal carcinoma in different age groups. A population-based investigation. Am J Gastroenterol 1997, 92:1505-1509.

5. Yamamoto S, Mochizuki H, Hase K, Yamamoto T, Ohkusa Y, Yokoyama S, Ushitani Y, Tamakuma S: Assessment of clinicopathologic features of colorectal mucinous adenocarcinoma. Am J Surg 1993, 166:257-261.

6. Wu CS, Tung S, Chen PC, Kuo YC: Clinicopathological study of colorectal mucinous carcinoma in Taiwan: A multivariate study. J Gastroenterol Hepatol 1996, 11:77-81.

7. Nozoe T, Anai H, Nasu S, Sugimachi K: Clinicopathological characteristics of mucinous carcinoma of the colon and rectum. J Surg oncol 2000 75:103-107.

8. Maksimovic S: Survival rates of patients with mucinous adenocarcinoma of the colorectum. Med Arh 2007, 61:26-29.

9. Kanemitsu $Y$, Kato T, Yasui $K$, Morimoto T, Shimizu $Y$, Kodera $Y$, Yamamura $Y$ : Survival after curative resection for mucinous adenocarcinoma of the colorectum. Dis Colon Rectum 2003, 46:160-167. 
10. Green JB, Timmcke AE, Mitchell WT, Hicks TC, Gathright JB Jr, Ray JE: Mucinous carcinoma -just another colon cancer? Dis Colon Rectum 1993, 36:49-54.

11. Ziprin P, Ridgway PF, Peck DH, Darzi AW: The theories and realities of port-site metastases: a critical appraisal. J Am Coll Surg 2002, 195:395-408.

12. Zmora O, Gervaz P, Wexner SD: Trocar site recurrence in laparoscopic surgery for colorectal cancer. Surg Endosc 2001, 15:788-793.

13. Lacy AM, Delgado S, Garcia-Valdecasas JC, Castells A, Pique JM, Grande L, Fuster J, Targarona EM, Pera M, Visa J: Port site metastases and recurrence after laparoscopic colectomy; a randomized trial. Surg Endosc 1998, 12:1039-1042.

14. Milsom JW, Böhm B, Hammerhofer KA, Fazio V, Steiger E, Elson P: A prospective, randomized trial comparing laparoscopic versus conventional techniques in colorectal cancer surgery: a preliminary report. J Am Coll Surg 1998, 187:46-54.

15. Franklin ME Jr, Rosenthal D, Abrego-Medina D, Dorman JP, Glass JL, Norem R, Diaz A: Prospective comparison of open vs laparoscopic colon surgery for carcinoma: five-year results. Dis Colon Rectum 1996, 39(10 suppl):s35-46.

16. Fleshman JW, Nelson H, Peters WR, Kim HC, Larach S, Boorse RR, Ambroze W, Leggett P, Bleday R, Stryker S, Christenson B, Wexner S, Senagore A, Rattner D, Sutton J, Fine AP: Early results of laparoscopic surgery for colorectal cancer; retrospective analysis of 372 patients treated by Clinical Outcomes of Surgical Therapy (COST) Study Group. Dis Colon Rectum 1996, 39(10 suppl):s53-58.

17. Curet MJ: Port site metastases. Am J Surg 2004, 187:705-712.

18. Votrubova J, Belohlavek O, Jaruskova M, Oliverius M, Lohynska R, Trskova K, Sedlackova E, Lipska L, Stahalova V: The role of FDG-PET/CT in the detection of recurrence colorectal cancer. Eur I Nucl med Mol Imaging 2006, 33:779-784.

19. Goshen E, Davidson T, Aderka D, Zwas ST: PET/CT detects abdominal wall and port site metastases of colorectal carcinoma. Br J Radiol 2006, 79:572-577.

20. Kosugi K, Ono M, Saito N, Sugito M, Ito M, Murakami K, Sato K, Kotaka M, Nomura S, Arai M, Kobatake T: Port site recurrence diagnosed by positoron emission tomography after laparoscopic surgery for colon cancer. Hepatogastroenterology 2005, 52:1440-1443.

21. Sarikaya I, Bloomston M, Povoski ST, Zhang J, Hall NC, Knopp MV, Martin EW Jr: FDG-PET scan in patients with clinically and/or radiologically suspicious colorectal cancer recurrence but normal CEA. World J Surg Oncol 2007, 5:64.

22. Rodriguez-Fernandez A, Gomez-Rio M, Llamas-Elvira JM, Ortega-Lozano S, Ferron-Orihuela JA, Ramia-Angel JM, Mansilla-Rosello A, Martinez-delValle MD, Ramos-Font C: Positron-emission tomography with fluorine-18fluoro-2- deoxy-D-glucose for gallbladder cancer diagnosis. Am J Surg 2004, 188:171-175.

23. Sun L, Su XH, Guan YS, Pan WM, Luo ZM, Wei JH, Wu H: Clinical role of 18F-fluorodeoxyglucose positron emission tomography/computed tomography in post-operative follow up of gastric cancer: initial results. World J Gastroenterol 2008, 14:4627-4632.

doi:10.1186/1477-7819-9-28

Cite this article as: Funahashi et al: A role of ${ }^{18} \mathrm{~F}$-fluorodeoxyglucose positron emission/computed tomography in a strategy for abdominal wall metastasis of colorectal mucinous adenocarcinoma developed after laparoscopic surgery. World Journal of Surgical Oncology 2011 9:28.

\section{Submit your next manuscript to BioMed Central and take full advantage of:}

- Convenient online submission

- Thorough peer review

- No space constraints or color figure charges

- Immediate publication on acceptance

- Inclusion in PubMed, CAS, Scopus and Google Scholar

- Research which is freely available for redistribution

Submit your manuscript at www.biomedcentral.com/submit
C Biomed Central 